\title{
0850 WATER SAFETY EDUCATION AS COMPULSORY PART OF SCHOOL CURRICULA IN EUROPE: A POTENTIAL MODEL FOR LOW AND MIDDLE INCOME COUNTRIES?
}

M MacKay*, J Vincenten, 0 Heller, M Peden Correspondence: European Child Safety Alliance, EuroSafe, P.0. Box 75169 Amsterdam 1070AD, Netherlands

\subsection{6/ip.2010.029215.850}

Water safety education programmes (including swimming lessons) for children over 5 years have been demonstrated to increase knowledge and improve swimming performance, thereby adding a layer of protection to prevent drowning. In order to increase participation in these programmes some countries in Europe have made such education a compulsory part of school curricula. The purpose of this study was to review existing policies in Europe regarding compulsory water safety education (including swimming lessons) as part of educational curricula in order to allow the development of recommendations for good practice. Policy and programme content, implementation and monitoring were also explored to inform effective transfer of the good practice to other settings, including low and middle income countries. An English language questionnaire was developed with input from the International Life Saving Federation and WHO and piloted in three countries. The questionnaire, which collected information on the existence, nature, monitoring of policies and issues related to content and implementation of resulting programmes, was sent the individual identified as the most appropriate in 31 countries. Data are available for 29 countries. Twenty-two reported some form of policy or programme, with 15 reporting national policies making water safety education including swimming lessons a compulsory part of educational curricula. Policies and resulting programmes varied greatly in content and implementation. Few had been evaluated or are monitored for impact. Analyses of findings identified several important issues with implications for future research and practice and transfer to low and middle income countries. 